\title{
Use of S1 nuclease in deep sequencing for detection of double-stranded RNA viruses
}

\author{
Saya SHIMADA ${ }^{1)}$, Makoto NAGAI ${ }^{1,2) *}$, Hiromitsu MORIYAMA ${ }^{3)}$, Toshiyuki FUKUHARA ${ }^{3)}$, Satoshi KOYAMA ${ }^{4)}$, \\ Tsutomu OMATSU²), Tetsuya FURUYA ${ }^{2,5)}$, Junsuke SHIRAI ${ }^{1,2)}$ and Tetsuya MIZUTANI ${ }^{2}$ \\ 1) Laboratory of Epizootiology, Cooperative Department of Veterinary Medicine Faculty and Agriculture, Tokyo University of Agriculture \\ and Technology, Saiwai, Fuchu, Tokyo 183-8509, Japan \\ 2) Research and Education Center for Prevention of Global Infectious Diseases of Animal, Tokyo University of Agriculture and \\ Technology, Saiwai, Fuchu, Tokyo 183-8509, Japan \\ ${ }^{3)}$ Laboratory of Molecular and Cellular Biology, Department of Applied Biological Science Faculty and Agriculture, Tokyo University of \\ Agriculture and Technology, Saiwai, Fuchu, Tokyo 183-8509, Japan \\ ${ }^{4)}$ Laboratory of Ethology, Cooperative Department of Veterinary Medicine Faculty and Agriculture, Tokyo University of Agriculture and \\ Technology, Saiwai, Fuchu, Tokyo 183-8509, Japan \\ ${ }^{5)}$ Laboratory of Microbiology, Department of Veterinary Medicine Faculty and Agriculture, Tokyo University of Agriculture and \\ Technology, Saiwai, Fuchu, Tokyo 183-8509, Japan
}

(Received 20 November 2014/Accepted 25 March 2015/Published online in J-STAGE 6 April 2015)

ABSTRACT. Metagenomic approach using next-generation DNA sequencing has facilitated the detection of many pathogenic viruses from fecal samples. However, in many cases, majority of the detected sequences originate from the host genome and bacterial flora in the gut. Here, to improve efficiency of the detection of double-stranded (ds) RNA viruses from samples, we evaluated the applicability of S1 nuclease on deep sequencing. Treating total RNA with S1 nuclease resulted in 1.5-28.4- and 10.1-208.9-fold increases in sequence reads of group A rotavirus in fecal and viral culture samples, respectively. Moreover, increasing coverage of mapping to reference sequences allowed for sufficient genotyping using analytical software. These results suggest that library construction using S1 nuclease is useful for deep sequencing in the detection of dsRNA viruses.

KEY WORDS: deep sequencing, double-stranded RNA viruses, group a rotavirus, next-generation sequencer, S1 nuclease

doi: 10.1292/jvms.14-0607; J. Vet. Med. Sci. 77(9): 1163-1166, 2015

Non-Sanger-based next-generation sequencing (NGS) is a comprehensive technology for the characterization of nucleic acid sequences, without prior knowledge of genetic background $[12,14]$. NGS has facilitated the discovery of many pathogenic viruses from a broad range of samples $[7,10]$. However, numerous sequence reads originating from bacterial species and hosts are recovered when using conventional metagenomic approaches. Thus, to detect viral genome sequence reads from minor virus populations efficiently, it is important to exclude contaminating nucleic acids, including those of bacteria and hosts. S1 nuclease was first identified in Aspergillus oryzae as an endonuclease specific for single-stranded (ss) polynucleotides $[1,2]$. S1 nuclease hydrolyzes ssRNA, ssDNA and ss regions of double-stranded (ds) polynucleotide, but it does not degrade dsRNA [3, 13, 15]. S1 nuclease was used in the present study, because it is inexpensive and easily inactivated by ethylenediaminetetraacetic acid.

Group A rotaviruses (RVAs) are major etiological agents of acute gastroenteritis, particularly in neonatal animals;

*Correspondence to: Nagai, M., Research and Education Center for Prevention of Global Infectious Diseases of Animal, Tokyo University of Agriculture and Technology, Saiwai, Fuchu, Tokyo 183-8509, Japan. e-mail: m-nagai@cc.tuat.ac.jp

(C)2015 The Japanese Society of Veterinary Science

This is an open-access article distributed under the terms of the Creative Commons Attribution Non-Commercial No Derivatives (by-nc-nd) License $<$ http://creativecommons.org/licenses/by-nc-nd/3.0/>.
RVAs can cause economic losses to the livestock industry $[4,11]$. RVAs possess a dsRNA genome composed of $11 \mathrm{ge}-$ nome segments [5]. Whole genome analyses of RVA based on their nucleotide sequences are important for comprehensive understanding of the evolution of RVAs, which involves genetic re-assortment events and interspecies transmission $[6,8]$. In a previous study, applying DNase I treatment to total RNA after RNA extraction markedly reduced the number of extra sequence reads in preliminary deep sequence analysis (data not shown). However, a considerable number of sequence reads from the RNA of bacterial species and hosts were detected in fecal and viral culture samples. In this study, to improve the efficiency of detection of dsRNA viruses from fecal and viral culture samples, we evaluated the applicability of S1 nuclease-treatment in deep sequencing.

Four fecal samples [2 from calves (calf no. 1: from 6 days old calf with diarrhea collected in 2013 in Japan and calf no. 2: from 26 days old calf with diarrhea collected in 2013 in Japan) and 2 from piglets (pig no.1: from healthy piglet collected in 2014 in Japan and pig no. 2: from piglet with diarrhea in 2014 in Japan)] and 3 viral culture samples were evaluated using the rapid antigen detection kit, Dipstick "Eiken" Rota immunochromatographic assay (Eiken Chemical Co., Ltd., Tokyo, Japan), for the presence of RVA. The results revealed that the samples from calf nos. 1 and 2 were weakly positive and positive, respectively, for RVA, while those from pig nos. 1 and 2 were strongly positive for RVA. The fecal samples were diluted $(1: 9[\mathrm{v} / \mathrm{v}])$ in sterile phosphate-buffered saline, centrifuged at $8,000 \times g$ for $10 \mathrm{~min}$ 
Table 1. Comparison of RVA sequence read counts and percentages of RVA sequence reads between non-treated and S1nuclease treated samples

\begin{tabular}{|c|c|c|c|c|c|c|c|c|}
\hline & & \multicolumn{4}{|c|}{ Fecal samples } & \multicolumn{3}{|c|}{ Viral culture samples } \\
\hline & & calf No.1 & calf No.2 & pig No.1 & pig No.2 & $\begin{array}{l}\text { bovine RVA } \\
\text { (G6P[5]) }\end{array}$ & $\begin{array}{l}\text { swine RVA } \\
\text { (G9P[23]) }\end{array}$ & $\begin{array}{l}\text { swine RVA } \\
\text { (G4P[23]) }\end{array}$ \\
\hline \multirow{2}{*}{$\begin{array}{l}\text { RVA sequence read } \\
\text { counts }\end{array}$} & non-treated & 2,190 & 24,737 & 30,768 & 366,339 & 1,901 & 975 & 34,499 \\
\hline & $\mathrm{S} 1$ nuclease treated & 62,260 & 140,402 & 401,860 & 539,964 & 398,850 & 181,870 & 347,478 \\
\hline \multirow{2}{*}{$\begin{array}{l}\text { percentage of RVA } \\
\text { sequence reads (\%) a) }\end{array}$} & non-treated & 0.9 & 9.4 & 5.4 & 75.0 & 0.5 & 0.2 & 7.9 \\
\hline & $\mathrm{S} 1$ nuclease treated & 21.1 & 47.3 & 98.3 & 98.6 & 93.0 & 33.1 & 99.4 \\
\hline
\end{tabular}

a) percentage of RVA sequence reads (\%): RVA sequence reads/total reads.

at $4^{\circ} \mathrm{C}$ and stored at $-80^{\circ} \mathrm{C}$ until further use. A bovine RVA (RVA/Cow-tc/JPN/Hori-No.14/1997/G6P[5]) and two swine RVA (RVA/Pig-tc/JPN/BU9/2014/G9P[23] and RVA/Pig-tc/ JPN/Miyamoto/1997/G4P[23]) were inoculated into MA104 cells. Supernatants were collected at post-inoculation day 5 and stored at $-80^{\circ} \mathrm{C}$, without centrifugation, until further use. Total RNA was extracted from all samples using TRIzol ${ }^{\circledR}$ LS Reagent (Life Technologies, Carlsbad, CA, U.S.A.), following which the RNA samples were treated with DNase I (0.5 U/ $\mu l$; TaKaRa Bio Inc., Otsu, Japan). Each RNA sample was divided into 2 equal volumes, of which one was left untreated and the other was treated with $\mathrm{S} 1$ nuclease ( $27 \mathrm{U} / \mu l$; TaKaRa Bio Inc.) at $23^{\circ} \mathrm{C}$ for $15 \mathrm{~min}$. After purification by ethanol precipitation, both the non-treated and S1 nuclease-treated samples were normalized to $50 \mathrm{ng} /$ reaction using a Qubit ${ }^{\circledR} 2.0$ Fluorometer (Invitrogen, Carlsbad, CA, U.S.A.). A cDNA library was constructed using the NEBNext $^{\circledR}$ Ultra $^{\text {TM }}$ RNA Library Prep Kit to facilitate sequencing with Illumina version 2.0 (New England Biolabs, Ipswich, MA, U.S.A.), according to the manufacturer's guidelines. Briefly, the RNA samples were fragmented and used to synthesize ds-cDNA, which was then purified using Agencourt $^{\circledR}$ AMPure ${ }^{\circledR}$ XP Beads (Beckman Coulter, Pasadena, CA, U.S.A.). To select fragments of approximately 200-bp in length after A-Tailing and adaptor ligation, 2 clean-up steps were performed using the beads. The library was then enriched by polymerase chain reaction (PCR), quantified using a Qubit ${ }^{\circledR} 2.0$ Fluorometer (Invitrogen) and sequenced using a MiSeq bench-top sequencer (Illumina, San Diego, CA, U.S.A.) with 51 single-end reads. The sequence data were analyzed using the MiSeq Reporter program (Illumina) to generate the reads in FASTQ format. Trimmed reads were assembled into contigs by de novo assembly with default parameters (automatic word and bubble size), using the CLC Genomics Workbench 6.0 (CLC; CLC bio, Aarhus, Denmark). Using the assembled contigs as references, consensus sequences for all the RVA segments were obtained. These consensus sequences were in turn used as references by the read mapper tool in CLC. The RVA sequence reads from the non-treated and S1 nuclease-treated samples were compared using mapping results of the read mapper tool with default mapping parameters (mismatch cost, 2; insertion cost, 3; deletion cost, 3 ; length function, 0.5 ; and similarity function, $0.8)$.

The results of the comparison of total RVA sequence read counts and percentage of RVA sequence reads (RVA sequence reads/total reads) between the non-treated and S1 nuclease-treated samples are listed in Table 1. The number of RVA sequence reads in all the genome segments was higher in the S1 nuclease-treated samples than in the non-treated samples. The percentage of RVA sequence reads was also higher in the S1 nuclease-treated samples than in the nontreated samples, particularly in the viral culture samples. Moreover, S1-treatment did not show any strong bias in relative numbers homologous to viral segments (Table 2).

Furthermore, RVA genotyping was performed by mapping the reads of the samples to the RVA reference sequences by using CLC[9]. Figure 1 illustrates the mapping results of the bovine fecal (calf no. 1) and swine fecal (pig no. 1) samples, which represent the VP4 bovine $(\mathrm{P}[1], \mathrm{P}[5], \mathrm{P}[11]$ and $\mathrm{P}[14]$; A) and VP7 swine genotypes (G2, G4, G5 and G9; B), respectively. Mapping sequence reads from the non-treated and $\mathrm{S} 1$ nuclease-treated samples to the reference sequences of representative strains revealed that the coverage of sequence reads of the S1 nuclease treated-samples against the reference sequences (calf no.1: 98.1\%, swine no.1: 97.7\%) was higher than that of the non-treated samples (calf no.1: $37.0 \%$, swine no. $1: 39.1 \%$ ).

In the present study, treating total RNA with S1 nuclease prior to NGS reduced the number of extra sequence reads and increased the number of reads of RVA obtained for the bovine fecal, swine fecal and viral culture samples. Furthermore, the increased number of sequence reads of RVA facilitated genotyping with mapping to reference sequences on the genome analysis software. These results suggest that S1 nuclease-treatment during preparation of viral RNA for NGS is more useful than DNase I treatment alone, for the detection of RVA and dsRNA viruses. S1 nuclease-treatment facilitates the detection of not only viruses belonging to the Reoviridae and Picobirnaviridae families, but also nonidentified novel viruses.

ACKNOWLEDGMENT. This study was supported by the Research Project for Improving Food Safety and Animal Health of the Ministry of Agriculture, Forestry and Fisheries of Japan.

\section{REFERENCES}

1. Ando, T. 1966. A nuclease specific for heat-denatured DNA in isolated from a product of Aspergillus oryzae. Biochim. Biophys. Acta 114: 158-168. [Medline] [CrossRef] 


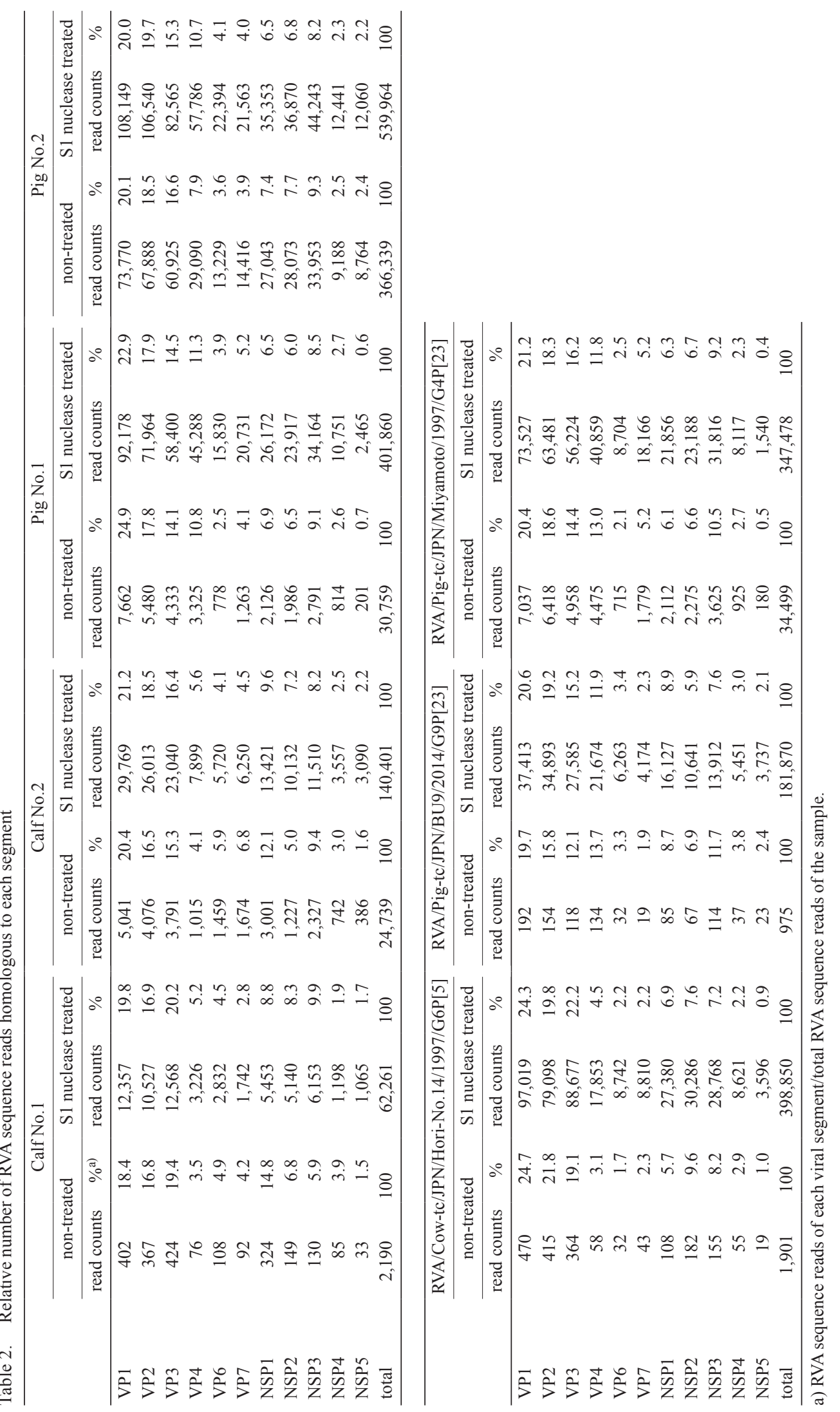


(A)

\begin{tabular}{r|l|l|l|} 
Reference sequence \\
S1 treated \\
non-treated coverage \\
Sequence depth. \\
coverage
\end{tabular}

(B)

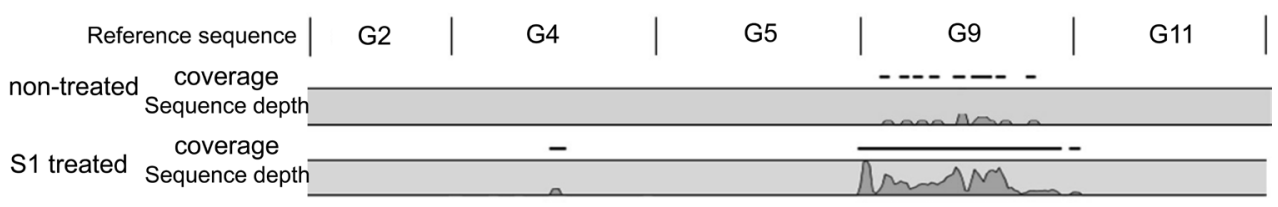

Fig. 1. Mapping of RVA sequence reads of non-treated and S1 treated samples of calf No.1 and swine No.1 against bovine reference sequences of (A) VP4 and (B) swine reference of VP7. Positional sequence coverage and sequencing depth of VP4 (P[1], P[5], P[11] and P[14]) and VP7 (G2, G4, G5, G9 and G11) of calf No.1 and swine No.1, based on reference assembly to P[1]: NCDV Lincoln (AB119636), P[5]: WC3 (AY05071), P[11]: B223 (D13394), P[14]: RVA/Cow-wt/JPN/Tottori-SG/2013/G15P[14] (AB853893), G2: RVA/Vaccine/USA/RotaTeq-SC2-9/G2P7 [5] (GU565068), G4: RVA/Vaccine/USA/RotaTeq-BrB-9/1996/G4P7[5] (GU565090), G5: RVA/Pig-tc/ESP/OSU-C5111/2010/G5P[7] (KJ450849), G9: JP3-6 (AB176678) and G11: HLJhg7 (JX498964).

2. Berk, A. J. and Sharp, P. A. 1978. Structure of the adenovirus 2 early mRNAs. Cell 14: 695-711. [Medline] [CrossRef]

3. Desai, N. A. and Shankar, V. 2003. Single-strand-specific nucleases. FEMS Microbiol. Rev. 26: 457-491. [Medline] [CrossRef]

4. Dhama, K., Chauhan, R. S., Mahendran, M. and Malik, S. V. 2009. Rotavirus diarrhea in bovines and other domestic animals. Vet. Res. Commun. 33: 1-23. [Medline] [CrossRef]

5. Estes, M. K. and Greenberg, H. B. 2013. Rotaviruses. pp. 1347-1401. In Fields Virology, 6th ed, (Knipe, D. M., Howley, P. M., Cohen, J. I., Griffin, D. E., Lamb, R. A., Martin, M. A., Racaniello, V. R. and Roizman, B. eds.), Lippincott, Philadelphia.

6. Ghosh, S. and Kobayashi, N. 2011. Whole-genomic analysis of rotavirus strains: current status and future prospects. Future Microbiol. 6: 1049-1065. [Medline] [CrossRef]

7. Marston, D. A., McElhinney, L. M., Ellis, R. J., Horton, D. L., Wise, E. L., Leech, S. L., David, D., de Lamballerie, X. and Fooks, A. R. 2013. Next generation sequencing of viral RNA genomes. BMC Genomics 14: 444. [Medline] [CrossRef]

8. Matthijnssens, J., Ciarlet, M., Heiman, E., Arijs, I., Delbeke, T., McDonald, S. M., Palombo, E. A., Iturriza-Gómara, M., Maes, P., Patton, J. T., Rahman, M. and Van Ranst, M. 2008. Full genome-based classification of rotaviruses reveals a common origin between human Wa-Like and porcine rotavirus strains and human DS-1-like and bovine rotavirus strains. J. Virol. 82: 3204-3219. [Medline] [CrossRef]

9. Minami-Fukuda, F., Nagai, M., Takai, H., Murakami, T., Ozawa,
T., Tsuchiaka, S., Okazaki, S., Katayama, Y., Oba, M., Nishiura, N., Sassa, Y., Omatsu, T., Furuya, T., Koyama, S., Shirai, J., Tsunemitsu, H., Fujii, Y., Katayama, K. and Mizutani, T. 2013. Detection of bovine group a rotavirus using rapid antigen detection kits, rt-PCR and next-generation DNA sequencing. J. Vet. Med. Sci. 75: 1651-1655. [Medline] [CrossRef]

10. Mokili, J. L., Rohwer, F. and Dutilh, B. E. 2012. Metagenomics and future perspectives in virus discovery. Curr. Opin. Virol. 2 63-77. [Medline] [CrossRef]

11. Papp, H., László, B., Jakab, F., Ganesh, B., De Grazia, S., Matthijnssens, J., Ciarlet, M., Martella, V. and Bányai, K. 2013. Review of group A rotavirus strains reported in swine and cattle. Vet. Microbiol. 165: 190-199. [Medline] [CrossRef]

12. Radford, A. D., Chapman, D., Dixon, L., Chantrey, J., Darby, A. C. and Hall, N. 2012. Application of next-generation sequencing technologies in virology. J. Gen. Virol. 93: 1853-1868. [Medline] [CrossRef]

13. Roberts, T. M., Bikel, I., Yocum, R. R., Livingston, D. M. and Ptashne, M. 1979. Synthesis of simian virus $40 \mathrm{t}$ antigen in Escherichia coli. Proc. Natl. Acad. Sci. U.S.A. 76: 5596-5600. [Medline] [CrossRef]

14. Schuster, S. C. 2008. Next-generation sequencing transforms today's biology. Nat. Methods 5: 16-18. [Medline] [CrossRef]

15. Vogt, V. M. 1973. Purification and further properties of singlestrand-specific nuclease from Aspergillus oryzae. Eur. J. Biochem. 33: 192-200. [Medline] [CrossRef] 